\title{
Designing high efficient solar powered lighting systems
}

Poulsen, Peter Behrensdorff; Thorsteinsson, Sune; Lindén, Johannes; Ploug, Rasmus Overgaard; Knott, Arnold; Mira Albert, Maria del Carmen; Mogensen, Ib; Retof, Kris

\section{Published in:}

Proceedings of IEEE 43rd Photovoltaic Specialist Conference 2016

Link to article, DOI:

10.1109/PVSC.2016.7750143

Publication date:

2016

Document Version

Peer reviewed version

Link back to DTU Orbit

Citation (APA):

Poulsen, P. B., Thorsteinsson, S., Lindén, J., Ploug, R. O., Knott, A., Mira Albert, M. D. C., Mogensen, I., \& Retof, K. (2016). Designing high efficient solar powered lighting systems. In Proceedings of IEEE 43rd

Photovoltaic Specialist Conference 2016 (pp. 2712-2714). IEEE. https://doi.org/10.1109/PVSC.2016.7750143

\section{General rights}

Copyright and moral rights for the publications made accessible in the public portal are retained by the authors and/or other copyright owners and it is a condition of accessing publications that users recognise and abide by the legal requirements associated with these rights.

- Users may download and print one copy of any publication from the public portal for the purpose of private study or research.

- You may not further distribute the material or use it for any profit-making activity or commercial gain

- You may freely distribute the URL identifying the publication in the public portal 


\title{
Designing high efficient solar powered lighting systems
}

\author{
Peter Behrensdorff Poulsen*,a , Sune Thorsteinsson ${ }^{\mathrm{a}}$, Johannes Lindén ${ }^{\mathrm{a}}$, Rasmus Overgaard Ploug ${ }^{\mathrm{b}}$, Arnold \\ Knott $^{\mathrm{b}}$, Maria del Carmen Mira Albert ${ }^{\mathrm{b}}$, Ib Mogensen ${ }^{\mathrm{c}}$, Kris Retoft ${ }^{\mathrm{c}}$ \\ ${ }^{a}$ Department of Photonics Engineering, Technical University of Denmark, Frederiksborgvej 399, Building \\ 130, 4000 Roskilde, Denmark, *ppou@fotonik.dtu.dk, phone: +45 46774572 \\ ${ }^{\mathrm{b}}$ Department of Electrical Engineering, Technical University of Denmark, Kgs. Lyngby, Denmark \\ ${ }^{\mathrm{c}}$ Outsider, Kigkurren 8A, DK-2300 København S, Denmark
}

\begin{abstract}
Some major challenges in the development of $\mathbf{L} 2 \mathbf{L}$ products is the lack of efficient converter electronics, modelling tools for dimensioning and furthermore, characterization facilities to support the successful development of the products. We report the development of 2 Three-Port-Converters respectively for $1-10 \mathrm{Wp}$ and $10-50 \mathrm{Wp}$ with a peak efficiency of $97 \%$ at $1.8 \mathrm{~W}$ of $\mathrm{PV}$ power for the $10 \mathrm{Wp}$ version. Furthermore, a modelling tool for $\mathrm{L} 2 \mathrm{~L}$ products has been developed and a laboratory for feeding in component data not available in the datasheets to the model is described.
\end{abstract}

\section{INTRODUCTION}

Due to the rapid increasing efficiency of light emitted diodes (LEDs) stand-alone combinations of PV module, battery storage and LED luminaires is becoming more attractive for a variety of lighting applications [1]. The systems operate entirely on DC and is often called Light-to-light (L2L) systems, see Fig. 1. Park lights and bollards are examples of $\mathrm{L} 2 \mathrm{~L}$ systems and these systems offers lighting solutions, for places where lighting is not feasible due to very high cabling costs of up to e.g. $\quad 700 € / \mathrm{m} \quad$ in Copenhagen and up to $2000 € / \mathrm{m}$ in Berlin [2]. Some of the major obstacles still remaining for successful L2L

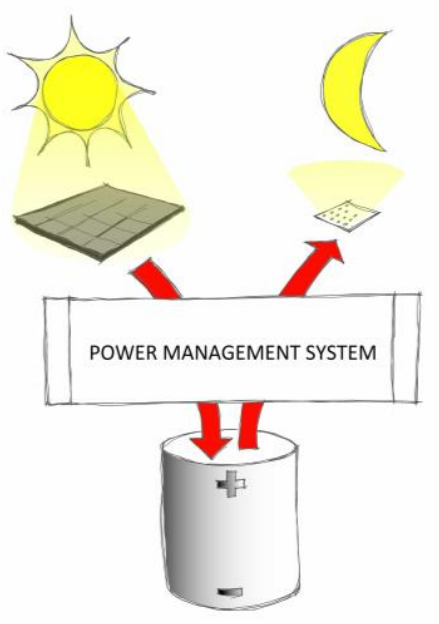

Fig. 1. A principle sketch of a Light-2-Light system. systems are 1) lack of efficient conversion electronics for small PV systems, (PV powers of 1-50 Wp) 2) lack of a dimensioning and assessment tool for L2L systems and 3) knowledge centers and laboratory facilities for supporting the complicated process of designing successful L2L products. The latter being an interdisciplinary technical task involving at least knowledge, tools, and test equipment for the technology fields of lighting, photovoltaics and power electronics. A series of Danish research projects has addressed these issues and the results are reported here.

\section{ELECTRONIC CONVERTER}

An electronic converter for outdoor light-to-light purposes should be able to work in two modes:

1. In the daytime: Convert energy from the PV panel while maintaining Maximum Power Point Tracking (MPPT) in order to harvest as much energy to the battery from the available solar energy as possible.

2. In the night: Convert stored energy from the battery to the operating point of the LED panel.

Hence this application calls for a Three-Port-Converter (TPC) with two operating modes as sketched in Fig. 2.

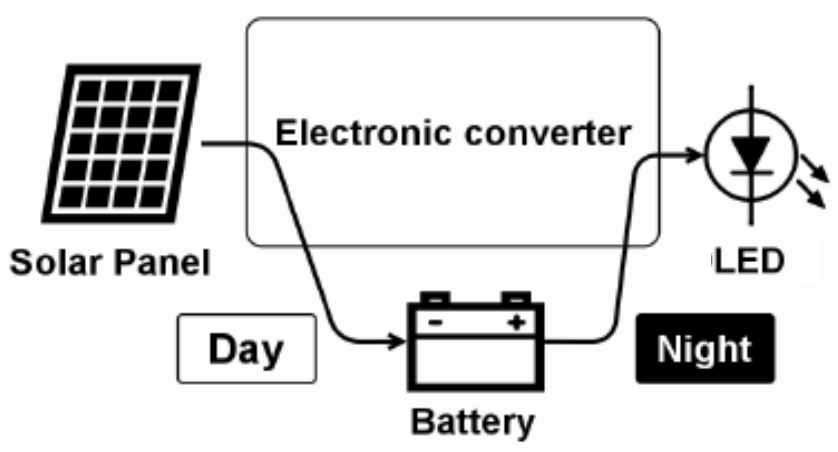

Fig. 2. Working principle of the converter

To cover the full range of $1-50 \mathrm{Wp}$ of solar panels with high efficiency, 2 versions of converters was developed. A low range for $\mathrm{PV}$ powers $1-10 \mathrm{Wp}$ and a high power range of 10$50 \mathrm{Wp}$, giving the versatility of choosing solar panels in the whole span. The efficiency curve for the $10 \mathrm{Wp}$ version is shown in Fig. 3. It is sought to achieve the peak conversion efficiency in the lower part of its operating range since L2L products often are placed in areas with a lot of shadows on the solar panels e.g. in parks or in the urban environments, making peak power operation rare. 


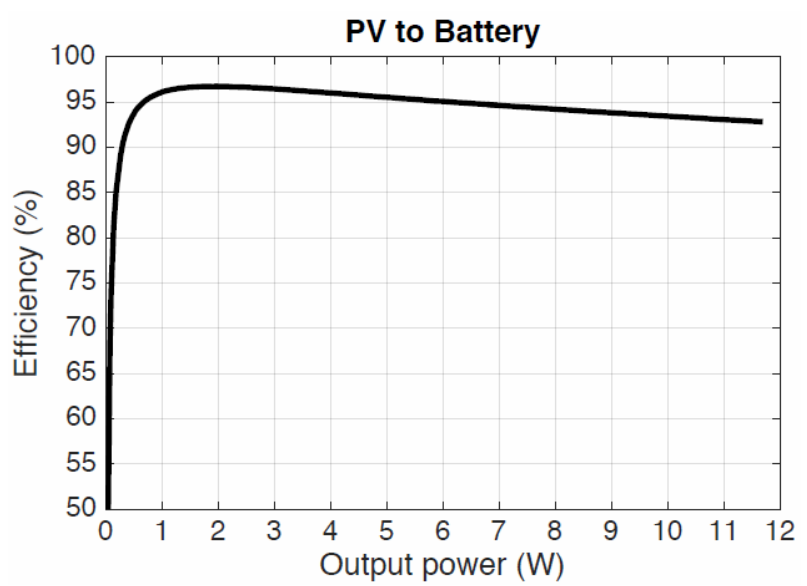

Fig. 3. Efficiency curve of the $10 \mathrm{~W}$ converter when harvesting energy from PV panel to the battery. It can be seen that the converter excels in having its highest efficiency at the lowest power obtaining $94 \%$ at $0.5 \mathrm{~W}$ and peaking at $97 \%$ at $1.8 \mathrm{~W}$.

The converters peak efficiency is $97 \%$ when operating at 1.8 $\mathrm{W}$. The conversion from battery to light is of similar efficiency. The electronics converter work is documented in [3] and [4].

\section{SOFTWARE FOR DIMENSIONING AND SIMULATION OF PV LED APPLICATIONS}

The authors have investigated several software tools on the market and none was found suited for the task of dimensioning and simulating performance of solar powered $\mathrm{L} 2 \mathrm{~L}$ products. A customized tool is therefore developed in MATLAB as a starting point with input from several specialized tools.

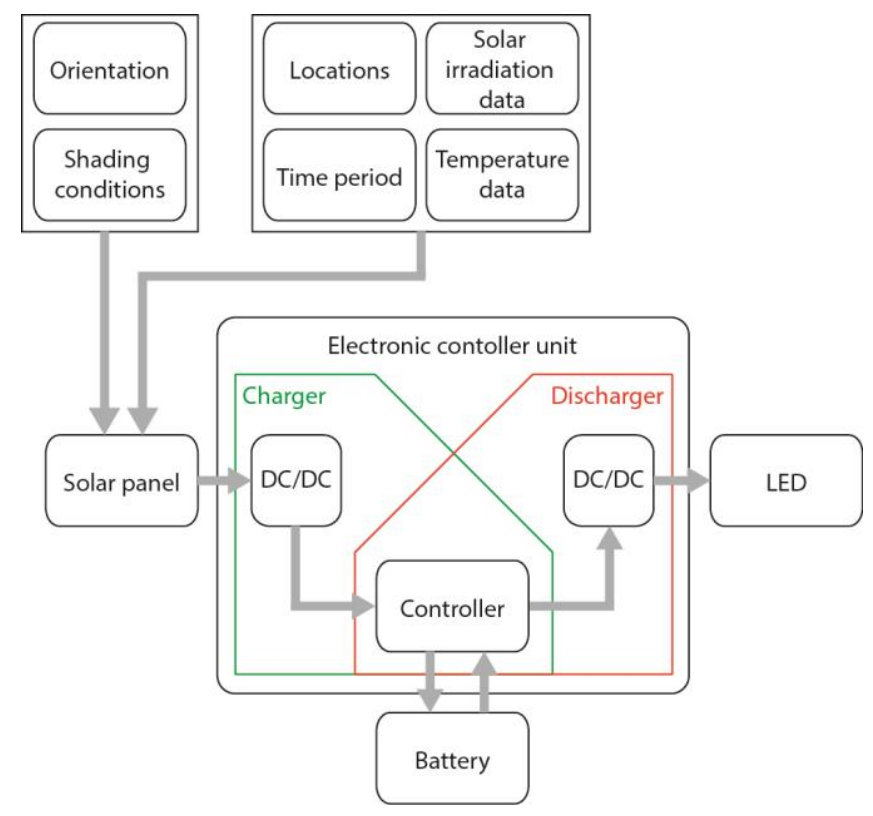

Fig. 4. Block diagram of L2L modelling tool.
The block diagram in Fig. 4. shows the design of the simulation tool, which essentially is a computer model of a basic PV application, including PV panel, electronics, battery and power consumption in the form of an LED luminaire. The L2L dimensioning tool differs since it uses highly time resolved weather data in 1-minute resolution. This is important when modelling solar products operating most of its time in the shadows from buildings and other artefacts. The efficiency curve in Fig. 3. of the developed converter is rather flat in the whole irradiation interval from $0-1$ sun. The full electronics controller unit, however, consist of both converter and controller with a microcontroller operating in several states, running algorithms, and controlling other external devices as a battery management system, motions sensors etc. The real energy conversion functions are therefore usually far from linear and depend heavily on irradiation level on the PV panel, temperature, battery voltage and other parameters which need to be modelled for precision. The energy flow is basically made up of

1. Energy flow from the sun to the PV panel

2. Energy flow from the panel - through the charger and into the battery

3. Energy flow from the battery - through the discharger - into the LEDs

4. Stand-by consumption of the electronics controller due the intelligent disposition of the energy for lighting (the lighting scheme) and the loss in its external components (if any).

The datasheets of small solar panels, PV/LED controllers and batteries are rarely having data for this type of modelling to be done.

\section{LABORATORY FOR CHARACTERIZATION OF L2L PRODUCTS}

A specialized laboratory has been built, to feed the mathematical simulation tool with accurate and sufficient data for modelling of L2L products and support the development of successful solar powered LED products. It is composed of the following facilities

\section{Component characterization}

- Solar cell electrical (I, V, Irradiation 0-1 sun AM 1.5)

- Solar panel electrical (I, V, Irradiation 0-1 sun AM 1.5)

- $\quad$ Battery (I, V, Charge, Temp)

- LED electrical and photometrical (I, V, lumens)

- Electronics controller

- Charging efficiency (Emulation of the PV panel and the battery, allowing mapping of the full operating range for the charger)

- Discharge efficiency (Vbat, L LED $_{\text {LED }} \mathrm{V}_{\text {LE }}$

- Shade measurement/simulation 


\section{Luminaire characterization}

- Spectroradiometry

- Photometry

- Goniospectroradiometry

- Goniophotometry

The measurements are tailored to fit into the L2L modelling tool and are more or less automated to characterize the individual components in the many different operating states needed. The luminaire characterization is not part of the model but a part of the process of creating highly efficient high end L2L products. The light rays need to illuminate the desired object nicely without the light being lost in reflectors and diffuser, giving rise to glare or other waste mechanisms. Here good optical engineering can reduce the total amount of light needed, and thus improving the efficiency. The relevant metric is useful lux or useful lumens which can be modelled by use of e.g. DIALux and RELUX which can be used iteratively with the L2L model.

\section{CASE}

Several products have been designed parallel in the process of developing the L2L converter electronics, the $\mathrm{L} 2 \mathrm{~L}$ simulation tool and L2L laboratory. The products were developed together with the company, Outsider, who is designing, producing and distributing high-end solar powered lighting product for the urban environments. 2 Products were developed together with Outsider and the Architecture company, Snøhetta, for the King Abdulaziz Centre for World Culture in Dhahran Saudi Arabia, see Fig. 5. below.

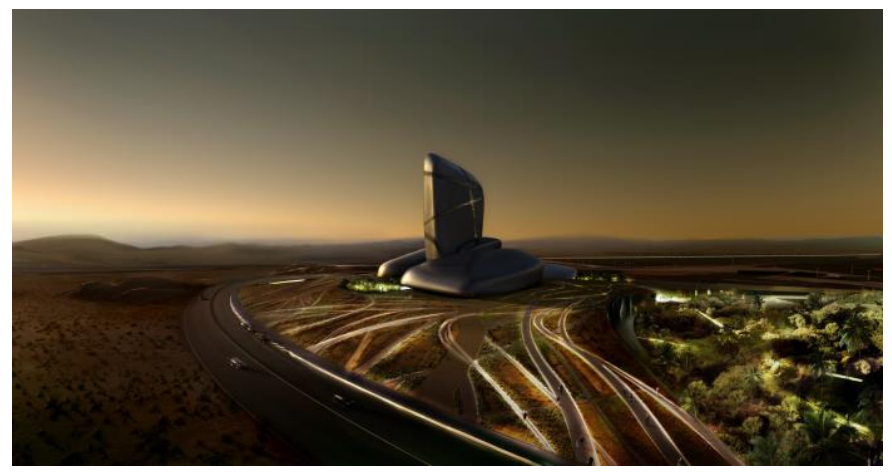

Fig. 5. King Abdulaziz Center for World Culture - Rendering Snøhetta/Mir.

One of the products are called LIGHT-TUBE and is inspired by bulrushes swaying gently in the wind, shown Fig. 6 . Especially the shade modelling was a special challenge of this product along with temperature modelling of the systems that had to be done to fit the data to the model. The PV is integrated in the base of the product and the LEDs in the end of the metal stick where luminaires is composed of edge-lit accryllic wave guides sandblasted on the sides.

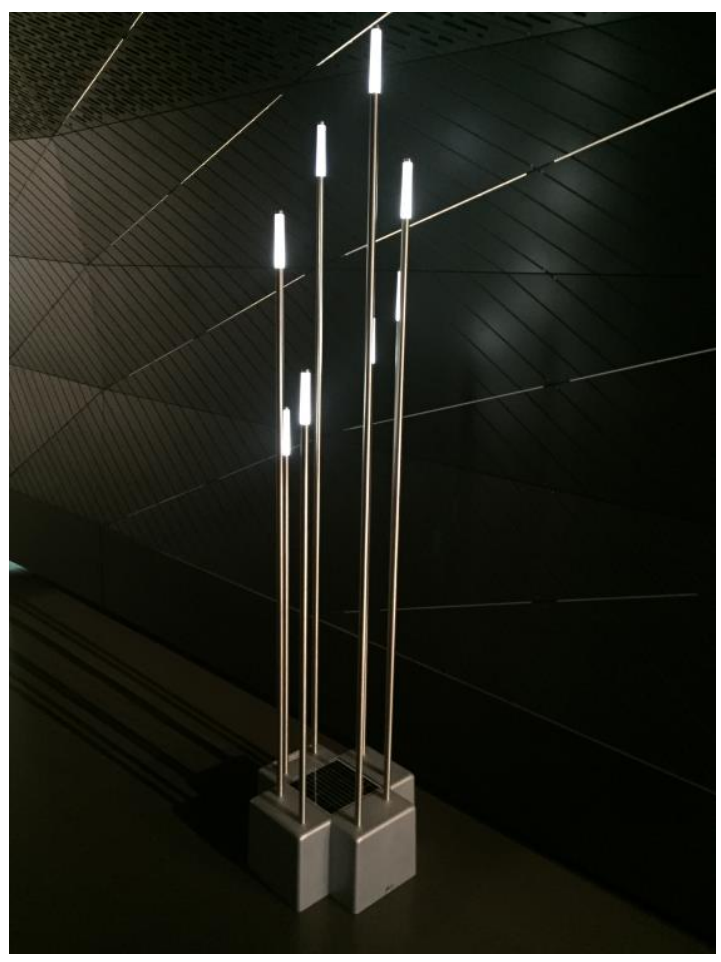

Fig. 6. LIGHT-TUBE

\section{SUMMARY}

3 major challenges in the development of L2L products is the lack of efficient converter electronics, modelling tools for dimensioning and furthermore, characterization facilities to support the successful development of the products. Above we report the development of 2 Three-Port-Converters respectively for $1-10 \mathrm{Wp}$ and $10-50 \mathrm{Wp} \mathrm{PV}$ panels with a peak efficiency of $97 \%$ at $1.8 \mathrm{~W}$ of $\mathrm{PV}$ power for the $10 \mathrm{Wp}$ version. Furthermore, a modelling tool for L2L products has been descriped and a laboratory for feeding in component data not available in the datasheets to the model is proposed.

\section{REFERENCES}

[1] D. L. Meier, L. Harvest, and S. Marys, "Stand-Alone Solar Generator with LED Floodlights for Outdoor Sign Illumination,", 40th IEEE Photovoltaic Specialist Conference, pp. 2748-2750, 2014.

[2] Poulsen, P.B. et al. , Udvikling af $\mathrm{CO} 2$ neutralt byrumsarmatur, Final report, ELFORSK project 343-021, www.elforsk.dk, 2013.

[3] Maria C. Mira, Arnold Knott and Michael A. E. Andersen, "Three-Port Converter for Low-Power Stand-Alone Light-toLight Systems (submitted for publication)", IEEE Energy Conversion Congress \& Expo, 2016.

[4] Rasmus Overgaard Ploug and Arnold Knott, "Photovoltaic OLED Driver for Low-Power Stand-Alone Light-to-Light Systems" (submitted for publication)", Elektronika ir Elektrotechnika, 2016 